\title{
Significant association of cagA positive Helicobacter pylori strains with risk of premature myocardial infarction
}

\author{
M Gunn, J C Stephens, J R Thompson, B J Rathbone, N J Samani
}

\begin{abstract}
Objective-To investigate whether genetic diversity of Helicobacter pylori influences its association with coronary heart disease, and specifically whether the risk is confined to infection with the more virulent strains bearing the cytotoxin associated gene-A (cagA) antigen.

Design and setting-Case-control study in hospital admitting unselected patients with myocardial infarction.

Methods and subjects-Serological status for cagA and $H$ pylori were determined in 342 cases of acute myocardial infarction and 214 population based control subjects free of clinical coronary heart disease.

Results-38.0\% of cases and $30.8 \%$ of controls were cagA seropositive (odds ratio 1.38, 95\% confidence interval $(\mathrm{CI}) 0.94$ to $2.01, \mathrm{p}=0.08)$. In subjects $<65$ years old $(153$ cases, 153 controls), cagA seropositivity was associated with a 1.80 -fold increase (95\% CI 1.07 to 3.03 , $p=0.02)$ in myocardial infarction risk, which increased further to 2.25 -fold (95\% CI 1.12 to $4.53, \mathrm{p}=0.01$ ) in subjects $<55$ years. There was no significant association of cagA status with classical coronary heart disease risk factors. $H$ pylori seropositivity was present in $60.2 \%$ of cases and $53.7 \%$ of controls (odds ratio $1.12,95 \%$ CI 0.83 to $1.51, \mathrm{p}=0.43$ ). H pylori seropositivity was not increased in young cases and did not show any interaction with age.

Conclusions-The association of chronic $H$ pylori infection with risk of myocardial infarction appears to be restricted to cagA bearing strains. The association is age dependent and stronger in younger subjects. Genetic heterogeneity of $H$ pylori may explain some of the discordant findings with regard to the association of $H$ pylor $i$ with coronary heart disease.

(Heart 2000;84:267-271)
\end{abstract}

Keywords: coronary heart disease; risk factors; Helicobacter pylori

Helicobacter pylori is a microaerophilic spiral shaped Gram negative bacterium that colonises the gastric lumen of humans and other primates. Infection is commonly acquired in childhood and is usually chronic. ${ }^{1}$ Raised concentrations of IgG antibodies to $H$ pylori are a fairly reliable indicator of the presence of infection. The bacterium is now recognised to be of major aetiological importance in peptic ulcer disease $^{2}$ and in gastric cancer. ${ }^{3}$ More recently, in conjunction with a variety of other chronic infections, interest in the possible association between $H$ pylori infection and coronary heart disease has developed. ${ }^{4}$ Mendall and colleagues were the first group to report a higher prevalence of $H$ pylori seropositivity in patients with coronary heart disease compared with healthy volunteers. ${ }^{5}$ However, subsequent studies have produced conflicting findings ${ }^{6-12}$ and the significance of the association remains uncertain. ${ }^{4}$ Confounding by the strong relation of $H$ pylori infection to other coronary heart disease risk factors such as age and social class may, at least partly, explain the contradictory results. However, recent studies have shown that there is also genetic diversity within $H$ pylori which affects its virulence. Specifically, strains bearing the cytotoxin associated gene-A (cagA) provoke a heightened inflammatory response in vivo ${ }^{13}$ and show a stronger relation with peptic ulcer disease ${ }^{14}$ and gastric cancer. ${ }^{15}$ There is increasing evidence, from both clinical and experimental observations, that inflammation plays an important role in coronary heart disease. ${ }^{16-18}$ Thus it is possible that any impact of $H$ pylori infection on coronary heart disease is crucially dependent on the type of infecting strain.

In a previous study ${ }^{9}$ comparing subjects with acute myocardial infarction with population based controls, we observed no overall association between $H$ pylori seropositivity and myocardial infarction risk despite adjustment for covariates. To investigate whether the type of $H$ pylori strain causing the infection is of relevance, we have analysed blood samples from our cohorts for anti-cagA antibodies as an indicator of infection with more virulent $H$ pylori strains. We report a significant and age dependent association of infection with cagA positive $H$ pylori strains and risk of myocardial infarction. Our findings suggest that genetic heterogeneity of $H$ pylori may explain some of the discordant findings with regard to the association of $H$ pylor $i$ with coronary heart disease.

\section{Methods}

SUBJECTS

The recruitment of patients and controls has been previously described. ${ }^{9}$ Briefly, patients who satisfied the World Health Organisation criteria for myocardial infarction ${ }^{19}$ were recruited from admissions to the coronary care 
Table 1 Characteristics of cases and controls

\begin{tabular}{|c|c|c|}
\hline & Cases $(n=342)$ & $\begin{array}{l}\text { Controls } \\
(n=214)\end{array}$ \\
\hline Age (years) ${ }^{\star}$ & $65.1(11.7)$ & $54.8(12.6)$ \\
\hline Male & $66.9 \%$ & $58.8 \%$ \\
\hline White & $88.0 \%$ & $92.9 \%$ \\
\hline History of hypertension ${ }^{\star}$ & $33.1 \%$ & $16.8 \%$ \\
\hline Diabetes $\star$ & $12.1 \%$ & $3.7 \%$ \\
\hline Current smoker* & $32.5 \%$ & $18.2 \%$ \\
\hline Angina & 28.3 & - \\
\hline Previous myocardial infarct & $19.3 \%$ & - \\
\hline Positive family history ${ }^{\star}$ & $38.2 \%$ & $25.1 \%$ \\
\hline $\mathrm{BMI}\left(\mathrm{kg} / \mathrm{m}^{2}\right)$ & $25.7(4.2)$ & $25.4(3.7)$ \\
\hline Total cholesterol $(\mathrm{mmol} / \mathrm{l})$ & $5.6(1.2)$ & $5.6(1.0)$ \\
\hline HDL cholesterol $(\mathrm{mmol} / \mathrm{l})$ & $1.2(0.3)$ & $1.2(0.3)$ \\
\hline
\end{tabular}

Values are mean (SD) or per cent of group.

${ }^{\star} \mathrm{p}<0.001$, cases $v$ controls.

$\mathrm{BMI}$, body mass index; HDL, high density lipoprotein.

unit (CCU) at Leicester Royal Infirmary. The CCU, serving a population of around 300 000, accounts for more than $65 \%$ of admissions of cases with myocardial infarction in Leicester. The period of recruitment was between July 1993 and April 1994, and more than 97\% of eligible subjects were recruited. Control subjects were recruited randomly from adult visitors to patients with non-cardiovascular illnesses on general medical and surgical wards at the Leicester Royal Infirmary, to provide subjects likely to be representative of the source population from which the cases came. Those reporting a history of myocardial infarction or angina were excluded from the analysis.

Cases and controls filled in a standard questionnaire about their personal histories, had height and weights measured, and provided blood samples for laboratory analysis. The study was approved by the local research ethics committee.

BIOCHEMICAL MEASUREMENTS

Serum total and high density lipoprotein (HDL) cholesterol were measured using a Kodak Ektachem E700 CXR automatic analyser in a quality controlled hospital biochemistry laboratory. For cases, the first blood sample taken after admission was used for the analysis.

DETERMINATION OF $H$ pylori AND cagA SEROLOGICAL STATUS

$H$ pylori status was determined serologically, as described previously, ${ }^{9}$ using an established IgG enzyme linked immunosorbent assay (ELISA) based on an ultracentrifuged sonicate antigen. IgG antibodies to the cagA protein were quantified on whole blood samples using a commercial ELISA kit (Helicobacter p120 (CAGA) ELISA, Viva Diagnostics, Hurth, Germany). The ELISA was validated by concurrent western blot

Table 2 Distribution of cagA seropositivity in cases and controls

\begin{tabular}{|c|c|c|c|c|c|c|}
\hline & \multicolumn{2}{|c|}{ Whole cohorts } & \multicolumn{2}{|c|}{$<65$ Years } & \multicolumn{2}{|c|}{$<55$ Years } \\
\hline & $\operatorname{cag} A^{+}$ & $\operatorname{cag} A^{-}$ & $\operatorname{cag} A^{+}$ & $\operatorname{cag} A^{-}$ & $\operatorname{cag} A^{+}$ & $\operatorname{cag} A^{-}$ \\
\hline Cases & 130 & 212 & 57 & 96 & 27 & 39 \\
\hline Controls & 66 & 148 & 38 & 115 & 28 & 91 \\
\hline Unadjusted & \multicolumn{2}{|c|}{$\begin{array}{l}\text { OR } 1.38(0.94 \text { to } 2.01) \\
p=0.08\end{array}$} & \multicolumn{2}{|c|}{$\begin{array}{l}\text { OR } 1.80(1.07 \text { to } 3.03) \\
p=0.02\end{array}$} & \multicolumn{2}{|c|}{$\begin{array}{l}\text { OR } 2.25(1.12 \text { to } 4.53) \\
p=0.01\end{array}$} \\
\hline Adjusted ${ }^{\star}$ & \multicolumn{2}{|c|}{ OR $1.20(0.81$ to 1.79$)$} & \multicolumn{2}{|c|}{$\begin{array}{l}\text { OR } 1.78 \text { (1.04 to } 3.03) \\
p=0.03\end{array}$} & \multicolumn{2}{|c|}{$\begin{array}{l}\text { OR } 2.20(1.09 \text { to } 4.41) \\
p=0.03\end{array}$} \\
\hline
\end{tabular}

*Adjusted for age and sex.

cagA $^{+} /$cagA $^{-}$, cagA seropositive/seronegative; OR, odds ratios with $95 \%$ confidence intervals. analysis of 207 of the samples, randomly chosen, to confirm the presence or absence of anti-cagA antibodies using a reference strain (NCTC 11637, National Collection of Type Cultures, London, UK) as antigen. Optimal sensitivity and specificity values were calculated for the assay from these data. Using an ELISA unit value of 5.2, 17 of 207 ELISA samples were false positive (that is, they had a unit value $\geqslant 5.2$, but no detectable anti-cagA antibody on immunoblot) and 16 of 207 ELISA samples were false negative (that is, a unit value of $<5.2$, but detectable anti-cagA antibody on immunoblot). Therefore, optimal sensitivity and specificity values were $86.7 \%$ and $85 \%$, respectively, for use of the ELISA on this study population.

\section{STATISTICAL ANALYSIS}

Distribution of cagA seropositivity and qualitative risk factors between cases and controls or qualitative risk factors between cagA positive and cagA negative cases or controls were compared using the $\chi^{2}$ test. Quantitative sample means were compared by analysis of variance. Logistic regression was used to analyse the effects of cagA seropositivity on myocardial infarction status and its interaction with linear age effect adjusted for sex. Adjustment was then made for other covariates by including them in the regression. The effects of these adjustments were tested by comparing the odds ratios associated with cagA and the corresponding age interaction term, when estimated with and without adjustment. ${ }^{20}$ In these analyses, age was adjusted for by pooling estimates made at different ages to obtain MantelHaenszel estimates and separately, by including a linear age term but no interaction, in a logistic regression. The changes in the odds ratio associated with cagA seropositivity adjusted for age were then plotted against the appropriate age cut off.

\section{Results}

In all, 556 subjects (342 cases, 214 controls) were analysed. Table 1 summarises their characteristics. Cases were significantly older than controls, and classical risk factors (hypertension, diabetes, smoking, and positive family history) were more prevalent in cases. Body mass index and total and HDL cholesterol concentrations were similar.

Three hundred and twenty one subjects were H pylori seropositive (206 of 342 cases $(60.2 \%)$ and 115 of 214 controls (53.7\%), odds ratio (OR) $1.12,95 \%$ confidence interval (CI) 0.83 to $1.51, \mathrm{p}=0.43) ; 196$ subjects were cagA seropositive. The distribution of cagA seropositivity in cases and controls is shown in table 2.

In the whole cohorts, $38.0 \%$ of cases and $30.8 \%$ of controls were cagA seropositive (odds ratio $1.38,95 \%$ CI 0.94 to $2.01, \mathrm{p}=0.08$ ). Because of the significant difference in age distribution of cases and controls we examined the potential impact of this on the association of cagA seropositivity with risk of myocardial infarction. In subjects under 65 years of age ( $\mathrm{n}=153$ cases, 153 controls) there was 1.80 fold $(p=0.02)$ increase in myocardial infarction risk associated with cagA seropositivity 


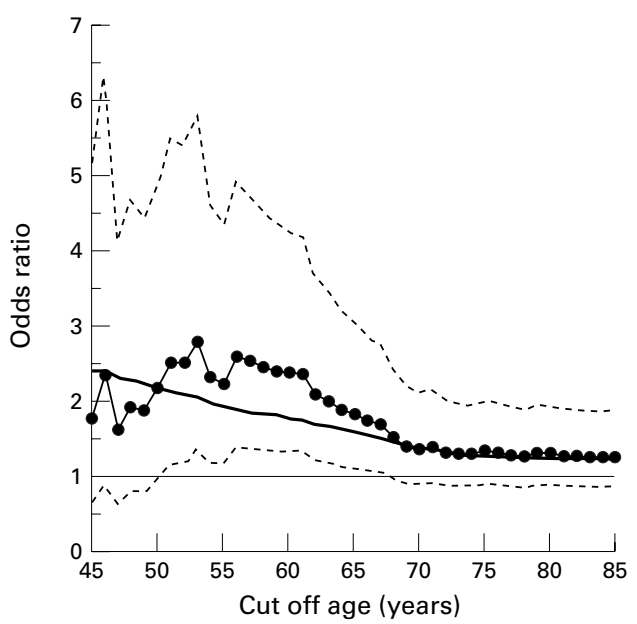

Figure 1 Age dependency of the association of cagA positive strains of $\mathrm{H}$ pylori with risk of myocardial infarction. The odds ratio estimates for risk of myocardial infarction associated with cagA seropositivity for different age cut off values from the Mantel-Haenszel analysis adjusted for age and sex are shown in the line with the closed circles (with 95\% confidence intervals in dotted lines). The corresponding estimates from the logistic regression are shown by the solid line.

(prevalence: cases $37.2 \%$, controls $24.8 \%$ ), which increased further to 2.25 -fold $(\mathrm{p}=0.01)$ in subjects less than 55 years old (prevalence: cases $40.9 \%$, controls $23.8 \%$ ) (table 2). The association remained significant in the younger age groups when adjusted for age and sex (table 2). In the Mantel-Haensel analysis, the age and sex adjusted odds ratio remained significant to an age of about 65 years (fig 1 ). A logistic regression analysis showed a significant interaction $(p=0.03)$ between age and the effect of cagA seropositivity on risk of myocardial infarction. The odds ratio associated with cagA seropositivity declined on average by $30 \%$ (95\% CI, 3-49\%) per decade (fig 1, solid line). Analysis for $H$ pylori seropositivity showed no similar increased risk in younger subjects ${ }^{9}$ or interaction with age (data not shown).

The distribution of risk factors in cases stratified by cagA status is shown in table 3 . There was no significant association of cagA status with any of the risk factors, and adjustment of the logistic regression for the covariates had no significant impact on either the overall association $(\mathrm{p}=0.85)$ or the interaction with age $(p=0.81)$. There was no significant association of any risk factors with cagA status in controls either (data not shown).

Table 3 Distribution of risk factors in cases according to cagA status

\begin{tabular}{llll}
\hline & cag $A^{+}$ & cag $A^{-}$ & $p$ Value \\
\hline Age (years) & $64.8(11.9)$ & $65.2(11.7)$ & 0.77 \\
Male & $65.4 \%$ & $67.9 \%$ & 0.63 \\
White & $85.4 \%$ & $89.6 \%$ & 0.24 \\
History of hypertension & $37.2 \%$ & $30.7 \%$ & 0.23 \\
Diabetes & $10.7 \%$ & $12.9 \%$ & 0.54 \\
Current smoker & $30.9 \%$ & $33.5 \%$ & 0.56 \\
Angina & $28.8 \%$ & $28.0 \%$ & 0.85 \\
Previous myocardial infarct & $19.7 \%$ & $19.0 \%$ & 0.89 \\
Positive family history & $37.5 \%$ & $38.6 \%$ & 0.88 \\
BMI (kg/m ${ }^{2}$ ) & $25.8(4.0)$ & $25.6(4.3)$ & 0.71 \\
Total cholesterol (mmol/1) & $5.7(1.3)$ & $5.6(1.2)$ & 0.43 \\
HDL cholesterol (mmol/1) & $1.25(0.35)$ & $1.20(0.34)$ & 0.34 \\
\hline
\end{tabular}

Data are mean (SD) or per cent of group.

$\mathrm{BMI}$, body mass index; cag $\mathrm{A}^{+} / \mathrm{cagA}^{-}$, cagA seropositive/seronegative; HDL, high density lipoprotein.

\section{Discussion}

Our finding in this study of a specific association between cagA positive strains of $H$ pylori and the risk of premature myocardial infarction adds to the current debate about the possible role of chronic bacterial infections in the pathogenesis of coronary heart disease. ${ }^{418}$ Studies to date on the role $H$ pylori have produced very conflicting results. ${ }^{5-12}$ Study size, study design, and the failure to control for potential confounding factors such as socioeconomic class have all been proposed as explanations for the contradictory findings. ${ }^{4} 18$ In this study we provide evidence that any effect of $H$ pylori infection on coronary heart disease risk may also be related to the type of infecting strain. Such risk appeared independent of classical risk factors for coronary heart disease.

The specific association of cagA positive $H$ pylori strains with myocardial infarction risk is biologically plausible. The cagA gene and the associated vacuolating cytotoxin (VacA) define type I $H$ pylori strains which produce a more pronounced gastric inflammatory response, including the induction of interleukin 6 and 8 and tumour necrosis factor $\alpha$, compared with type II (cagA negative) strains, ${ }^{13}{ }^{21}$ and are more strongly associated with peptic ulcer disease ${ }^{14}$ and gastric tumours. ${ }^{15}$ Recent studies have shown that this enhanced response in type I strains reflects the presence of a $40 \mathrm{~kb}$ DNA insertion flanking cagA (the cag region), which has the typical features of a pathogenicity island (PAI) encoding for several virulent factors which promote the inflammatory response. ${ }^{22}$ Increasing evidence suggests that inflammation (both systemically as well as locally) plays an important role in the development of coronary heart disease and particularly the progression to acute coronary syndromes. ${ }^{16-18}$ Systemic markers of inflammation such as $\mathrm{C}$ reactive protein and acute phase reactants such as fibrinogen and serum amyloid A have been shown to be associated prospectively with myocardial infarction risk, ${ }^{23-28}$ and part of the beneficial effects of aspirin on coronary risk may be related to its anti-inflammatory rather than its antiplatelet effect. ${ }^{28}$ Thus it is possible that cagA positive $H$ pylori strains increase the risk of myocardial infarction through the promotion of an enhanced inflammatory response. Indeed, $H p y$ lori seropositivity has been associated with raised concentrations of fibrinogen and $\mathrm{C}$ reactive protein, ${ }^{29}{ }^{30}$ although, as in the case of the association with coronary heart disease, results have been mixed; a recent meta-analysis ${ }^{31}$ suggested that the correlations reflected chance or publication bias. However, studies in such populations have not taken into account the genetic heterogeneity of $\mathrm{H}$ pylori.

The association of cagA positive $H$ pylori strains with coronary heart disease has also been examined by Pasceri and colleagues. ${ }^{32}$ In 88 patients with ischaemic heart disease (mean (SD) age 57 (8) years, $74 \mathrm{men}$ ) and in 88 matched controls, they observed a 3.8 -fold adjusted increase in risk of ischaemic heart disease in cagA positive subjects (prevalence of 
cagA seropositivity: cases $43 \%$, controls $17 \%$ ). Interestingly, they also observed an increase in overall prevalence of $H$ pylori seropositivity in cases $(62 \% v 40 \%)$. Prevalence of cagA negative strains was similar in patients and controls $(19 \%$ v 23\%). Pasceri and colleagues studied patients with a range of coronary syndromes including severe unstable angina, acute myocardial infarction, and chronic stable angina, while our larger study was focused on acute myocardial infarction only. Although the prevalence of infection by cagA positive strains was similar in Pasceri's three patient groups, further studies are needed to define the precise relation of infection with cagA bearing strains with different coronary syndromes, especially as a recent study by Koenig and colleagues found no association in 312 patients with stable coronary heart disease compared with 479 control subjects. ${ }^{33}$ However, our findings emphasise the point that the ability to detect any overall association of $H$ pylori seropositivity with coronary heart disease may depend not only on the population prevalence of $H$ pylori infection but also on the relative proportion infected with cagA positive strains. Studies have shown there is wide variation $(28-82 \%)$ in cagA seroprevalence in different countries. ${ }^{34}$

The finding that the association of risk of myocardial infarction with cagA positive $H p y$ lori strains was age dependent is not entirely unexpected as the associations of most vascular risk factors with coronary heart disease tend to be stronger in younger than in older individuals. Although this is the most likely explanation, it needs also to be noted that several studies have shown that the accuracy of serological testing for $H$ pylori, and in particular the specificity, declines with age. ${ }^{35}$ The reasons for this are unclear but cross reactivity between antibodies owing to increased antigenic exposure with age may be a factor. However, although this could explain why an association was not observed in older subjects in our study, it is important to emphasise that it does not affect the significance of the association seen in subjects under 65 years.

\section{LIMITATIONS}

Our study has several limitations common to cross sectional studies. In particular we cannot exclude the possibility that unrecognised population stratification for relevant factors influenced the findings. Specifically, socioeconomic status is known to affect both the prevalence of $H$ pylori infection and the risk of coronary heart disease. ${ }^{418}$ Although our controls were recruited from hospital visitors, specifically to provide healthy subjects likely to be representative of the source population from which the cases came, details of socioeconomic status were not obtained, and we were not able to adjust for this. However, the specific association with cagA seropositivity in the absence of an overall increase in $H$ pylori prevalence in cases argues against this being the explanation for the finding. Another limitation is that, although the effect of infection with cagA strains appeared independent of classical coronary heart disease risk factors, the study does not provide direct mechanistic information. Therefore, the association of cagA positive strains of $H$ pylori on risk of coronary heart disease needs to be confirmed in furtherideally prospective-studies, and whether the effect is mediated through an enhanced inflammatory response needs to be determined. Such studies are worthwhile not only because they may provide important insights on the pathophysiological basis of coronary syndromes, but also because of the considerable potential, if the association is proven, of new forms of therapeutic and preventative treatments directed towards infection eradication.

1 Graham DY, Malaty HM, Evans GE, et al. Epidemiology of Helicobacter pylori in an asymptomatic population in the United States. Gastroenterology 1991;100:1495-501.

2 Kurata JH, Nogawa AN. Meta-analysis of risk factors for peptic ulcer: nonsteroidal anti-inflammatory drugs, Helicobacter pylori, and smoking. 7 Clin Gastroenterol 1997;24:217.

3 Blaser MJ, Chyou PH, Nomura A. Age at establishment of Helicobacter pylori infection and gastric carcinoma, gastric ulcer, and duodenal ulcer risk. Cancer Res 1995;55:562-5.

4 Danesh J, Collins R, Peto R. Chronic infections and coronary heart disease: is there a link? Lancet 1997;350:430-6.

5 Mendall MA, Goggin PM, Molineaux N, et al. Relation of Helicobacter pylori infection and coronary heart disease. Br Heart f 1994;71:437-9.

6 Patel P, Mendall MA, Carrington D, et al. Association of Helicobacter pylori and Chlamydia pneumoniae infections with coronary heart disease and cardiovascular risk factors [correction appears in BMF 1995;311:985]. BMF 1995; 311:711-14

7 Murray LJ, Bamford KB, O'Reilly DP, et al. Helicobacter pylori infection: relation with cardiovascular risk factors, ischaemic heart disease, and social class. Br Heart 7 1995; 74:497-501.

8 Whincup PH, Mendall MA, Perry IJ, et al. Prospective relations between Helicobacter pylori infection, coronary heart disease and stroke in middle aged men. Heart 1996;75: 568-72.

9 Rathbone B, Martin D, Stephens J, et al. Helicobacter pylori seropositivity in subjects with acute myocardial infarction. Heart 1996;76:308-11.

10 McDonagh TA, Woodward M, Morrison CE, et al. Helicobacter pylori infection and coronary heart disease in the North Glasgow MONICA population. Eur Heart $\mathcal{f}$ 1997;18:1257-60.

11 Wald NJ, Law MR, Morris JK, et al. Helicobacter pylori infection and mortality from ischaemic heart disease: negative results from a large, prospective study. BMf 1997;315: 1199-201.

12 Danesh J, Youngman L, Clark S, et al. Helicobacter pylori infection and early onset myocardial infarction: casecontrol and sibling pairs study. BMF 1999;319:1157-62.

13 Peek RM, Miller GG, Tham KT, et al. Heightened inflammatory response and cytokine expression in vivo to cagA+ matory response and cytokine expression in vivo to cag

14 Ching CK, Wong BC, Kwok E, et al. Prevalence of cagA-bearing Helicobacter pylori strains detected by the anti-cagA assay in patients with peptic ulcer disease and in controls. Am f Gastroenterol 1996;91:949-53.

15 Blaser MJ, Perez-Perez GI, Kleanthous H, et al. Infection with Helicobacter pylori strains possessing cagA is associated with an increased risk of developing adenocarcinoma of the stomach. Cancer Res 1995;55:2111-15.

16 Ross R. The pathogenesis of atherosclerosis: a perspective for the 1990s. Nature 1993;362:801-8.

17 Entman ML. Ballantyne CM. Inflammation in acute coronary syndromes. Circulation 1993;88:800-3.

18 Ridker PM. Inflammation, infection, and cardiovascular risk: how good is the clinical evidence? Circulation 1998;97: 1671-4.

19 WHO (Report of the joint International Society and Federation of Cardiology/World Health Organisation Task Force on standardization of clinical nomenclature). Nomenclature and criteria for diagnosis of ischaemic heart disease. Circulation 1979;59:607-9.

20 Mickey RM, Greenland S. The impact of confounder selection criteria on effect estimation. Am $\mathcal{F}$ Epidemiol 1989;129: 125-37.

21 Yamaoka Y, Kita M, Kodama T, et al. Induction of various cytokines and development of severe mucosal inflammation by cagA gene positive Helicobacter pylori strains. Gut 1997;41:442-51.

22 Censini S, Lange C, Xiang Z, et al. cag, a pathogenicity island of Helicobacter pylori, encodes type I-specific and disease-associated virulence factors. Proc Natl Acad Sci USA 1996;93:14648-53.

23 Liuzzo G, Biasucci LM, Gallimore JR, et al. The prognostic value of C-reactive protein and serum amyloid A protein in severe unstable angina. $N$ Engl f Med 1994;331:417-24. 
24 Thompson SG, Kienast J, Pyke SDM, et al. Hemostatic factors and the risk of myocardial infarction or sudden death in patients with angina pectoris: European Concerted Action on Thrombosis and Disabilities Angina Pectoris Study Group. N Engl f Med 1995;332:635-41.

25 Kuller LH, Tracy RP, Shaten J, et al. for the MRFIT Research Group. Relationship of C-reactive protein and coronary heart disease in the MRFIT nested case-control study. Am F Epidemiol 1996;144:537-47.

26 Haverkate F, Thompson SG, Pyke SDM, et al. for the European Concerted Action on Thrombosis and Disabilities Angina Pectoris Study Group. Production of C-reactive protein and risk of coronary events in stable and unstable angina. Lancet 1997;349:462-6.

27 Fyfe AI, Rothenberg LS, DeBeer FC, et al. Association between serum amyloid A proteins and coronary artery disease: evidence from two distinct arteriosclerotic processes. Circulation 1997;96:2914-19.

28 Ridker PM, Cushman M, Stampfer MJ, et al. Inflammation, aspirin, and the risk of cardiovascular disease in apparently aspirin, and the risk of cardiovascular disease

29 Patel P, Carrington D, Strachan DP, et al. Fibrinogen: a link between chronic infection and coronary heart disease. Lancet 1994;343:1634-5.
30 Mendall MA, Patel P, Ballam L, et al. C reactive protein and its relation to cardiovascular risk factors: a population

31 Danesh J, Peto R. Risk factors for coronary heart disease and infection with Helicobacter pylori: meta-analysis of 18 studies. BMF 1998;316:1130-2.

32 Pasceri V, Cammarota G, Patti G, et al. Association of virulent Helicobacter pylori strains with ischemic heart disease. Circulation 1998;97:1675-9.

33 Koenig W, Rothenbacher D, Hoffmeister A, et al. Infection with Helicobater pylori is not a major independent risk factor for stable coronary heart disease: lack of effect of cytotoxin-associated protein A-positive strains and absence of systemic inflammatory response. Circulation 1999;100: 2326-31.

34 Perez-Perez GI, Bhat N, Gaensbauer J, et al. Countryspecific constancy by age in cagAt proportion of spelicin of

35 Schembri commercial diagnostic tests for Helicobacter pylori antibodies. F Clin Microbiol 1993;31:2621-4.

36 Stevens M, Livsey S, Swann RA, Rathbone BJ. Sixteen ELISAs for the detection of antibodies to Helicobacter pylori (MDA/97/55). London: HMSO, 1997:1-46.

\section{IMAGES IN CARDIOLOGY}

\section{Mycotic aneurysm formation with dehiscence of a valved aortic conduit resulting in dynamic aortic obstruction}

A 67 year old man presented with acute breathlessness, sharp chest pain radiating to the back on swallowing, and a two month history of "flu like" symptoms. One year previously he had undergone elective implantation of a $25 \mathrm{~mm}$ Carboseal valved aortic conduit for severe aortic regurgitation caused by annuloaortic ectasia. Blood pressure was 85/ $60 \mathrm{~mm} \mathrm{Hg}$, temperature was $38^{\circ} \mathrm{C}$, and there was a harsh ejection systolic murmur and a quiet aortic diastolic murmur. Transthoracic echocardiography revealed an $8 \mathrm{~cm}$ mycotic false aneurysm around the aortic conduit and cranial systolic displacement of the valve by up to $1 \mathrm{~cm}$. Transoesophageal echocardiography confirmed proximal dehiscence of the valved conduit with vegetations but no valvar regurgitation and a large mycotic abscess. During systole, false aneurysm pressure exceeded aortic pressure, leading to collapse of the aortic conduit and generation of a dynamic pressure gradient of $100 \mathrm{~mm} \mathrm{Hg}$ (top) (LVOT, left ventricular outflow tract; A, false aneurysm; L, conduit lumen). In diastole, falling pressure in the false aneurysm restored the normal lumen of the conduit (bottom). There was a small amount of retrograde diastolic flow into the aneurysm at the distal suture line in the mid ascending aorta.

At emergency surgery, the valved prosthesis was almost completely dehissed from the annulus, with extensive vegetations. The outer wall of the false aneurysm was formed from fibrous tissue and laminated thrombus, and there was a small defect in the distal aortic suture line. An aortic homograft was inserted
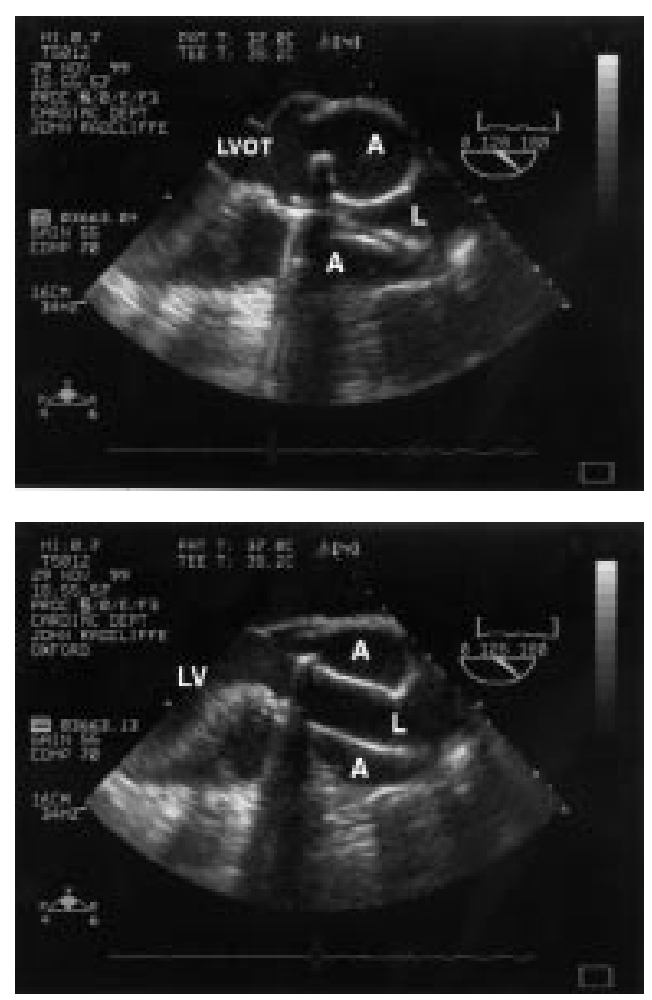

successfully. Multiple blood cultures grew Propionibacterium species sensitive to penicillin, and the patient was discharged after six weeks of antibiotic treatment.

N R A CLARKE

A P BANNING 